\title{
HPTLC METHOD FOR ESTIMATION AND QUANTIFICATION OF $\beta$-SITOSTEROL FROM IN-VIVO AND IN-VITRO SAMPLES OF MERREMIA AEGYPTIA AND MERREMIA DISSECTA
}

\author{
RIDHI JOSHI*, RISHIKESH MEENA, PREETI MISHRA, VIDYA PATNI
}

Department of Botany, Plant Pathology, Tissue Culture and Biochemistry Laboratory, University of Rajasthan, Jaipur, India. Email: ridhi.joshi316@gmail.com

Received: 10 June 2020, Revised and Accepted: 20 July 2020

\section{ABSTRACT}

Objective: A normal-phase high-performance thin-layer chromatography (HPTLC) method has been developed and validated for estimation and quantitation of beta-sitosterol from the methanolic fraction of different plant parts of two medicinally important plants viz. Merremia aegyptia and Merremia dissecta. These plants have been reported to possess antimicrobial, antioxidant, and anti-inflammatory activities.

Methods: Chromatographic separation of beta-sitosterol from the methanolic extracts of plant parts of $M$. aegyptia and $M$. dissecta was performed on TLC aluminum plates pre-coated with silica gel $60 \mathrm{~F}_{254}$ using a suitable mobile phase. The densitometric scanning was done after derivatization at $\lambda-580 \mathrm{~nm}$ for $\beta$-sitosterol.

Result: Only $M$. dissecta leaf sample was reported to contain $\beta$-sitosterol ( $4.6 \mathrm{ng} / \mu \mathrm{l})$, whereas other samples such as seed, stem, and callus extracts of M. aegyptia and $M$. dissecta did not showed its presence.

Conclusion: The developed HPTLC method is simple, rapid, and precise and can be used for routine analysis and quantification of $\beta$-sitosterol and other useful plant bioactives that are phytopharmaceutically important.

Keywords: High-performance thin-layer chromatography, Derivatization, Anti-inflammatory, Merremia aegyptia, Merremia dissecta.

(C) 2020 The Authors. Published by Innovare Academic Sciences Pvt Ltd. This is an open access article under the CC BY license (http://creativecommons. org/licenses/by/4. 0/) DOI: http://dx.doi.org/10.22159/ajpcr.2020.v13i10.38983

\section{INTRODUCTION}

High-performance thin-layer chromatography (HPTLC) employs the principle of adsorption for separation. The mobile phase solvent moves according to capillary action. Different components of the solution separate according to their affinities toward the adsorbent. The component with more affinity toward the stationary phase travels slower and vice versa. However, it has certain limitations such as having limited developing distance and low plate efficiency as compared to high-performance liquid chromatography (HPLC) and gas chromatography still it is widely used for quality evaluation due to its simplicity, low cost, and requirements.

HPTLC is used to assess, compare, and quantify the reservoirs of secondary metabolites in different plants and also can be used in fingerprinting as conducted by Dawane and Fulekar [1] in which the results obtained by HPTLC fingerprinting method were found reliable, accurate, and economical for identification and authentication of Avicennia marina mangrove species from other similar mangroves, in a single TLC plate run.

Plant sterols (or phytosterols) are a naturally occurring part of all plants and are found in nuts, legumes, grains, cereals, wood pulp, and leaves. Phytosterols are similar in structure to cholesterol in the human body and therefore block cholesterol from being absorbed. $\beta$-sitosterol is one such phytosterol having properties such as reducing cholesterol levels, activities of cancer cells, promoting prostate gland health, and immunity enhancement in the human body (Fig. 1).

Molecular formula : $\quad \mathrm{C}_{29} \mathrm{H}_{50} \mathrm{O}$

Molar mass : $\quad 302.236 \mathrm{~g} / \mathrm{mol}$

Melting point $\quad: \quad 135^{\circ} \mathrm{C}-137^{\circ} \mathrm{C}$

The structures of beta-sitosterol are quite similar to cholesterol, thus can inhibit the absorption of cholesterol in the body [2], reducing its levels in the plasma [3]. The liver function activity (GDP, GOP) can be improved with $\beta$-sitosterol [4], and it can also reduce prostate and colon cancer cell growth [5]. The presence of $\beta$-sitosterol in foods suppresses carcinogenesis. It can also be the factor in forming the lymph cells and Natural Killer cells in the immunity process circulation [6]. $\beta$-sitosterol in corn oil, rice bran oil, and other vegetable oil decreases the cholesterol level in the plasma [7].

It has antifungal, antibacterial, and anti-inflammatory activities and can be used to treat asthma, arthritis, allergies, and cancer [8]. It was isolated from tissue cultures of Balanites aegyptiaca [9]. The HPTLC analysis of Asparagus racemosus, Withania somnifera, Vitex negundo, Plumbago zeylanica, Butea monosperma, and Tephrosia purpurea extracts was investigated [10].

The present study was undertaken for identification and quantification of $\beta$-sitosterol from in vivo and in vitro plant parts of Merremia aegyptia and Merremia dissecta.

\section{METHODS}

Preparation of extracts

Plant parts such as leaves, stems, seeds, and calli of M. aegyptia and M. dissecta were dried in the dark at room temperature, powdered and methanol extracted by Soxhlet extractor. Afterward, the extracts were

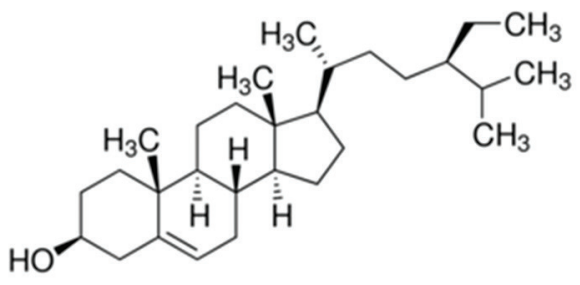

Fig. 1: Chemical structures of $\beta$ sitosterol 
filtered using Whatman filter paper no. 42 and the solvents obtained were dried in a rotary vacuum evaporator.

\section{Reagents and other materials}

$\beta$-sitosterol (Sigma Aldrich), toluene, ethyl acetate, and methanol (all reagents of analytical grade, (E-Merck) and silica gel $60 \mathrm{~F}_{254}$ pre-coated TLC aluminum plates (E-Merck) were used for the analysis.

\section{Preparation of standard and sample solutions}

Ten-milligram $\beta$-sitosterol was dissolved in $10 \mathrm{ml}$ methanol $(1 \mathrm{mg} / \mathrm{ml})$. The Soxhlet extracted and dried methanolic extracts were accurately weighed (100 mg) and dissolved in methanol and then solution was filtered through Whatman filter paper no. 42 and the filtrate was made up to the mark with methanol.

\section{Procedure}

The samples were spotted in the form of bands with CAMAG microliter syringe on a TLC A1 pre-coated silica gel plates $60 \mathrm{~F}_{254}(10 \mathrm{~cm} \times 10 \mathrm{~cm}$ with $0.2 \mathrm{~m}$ thickness, E. Merck) using CAMAG Linomat V applicator. 10 $\mu \mathrm{l}$ of test solution and standard solution was applied on pre-coated layer maintaining a distance of $10 \mathrm{~mm}$ from the bottom edge, band length 6 $\mathrm{mm}$, distance between tracks $10 \mathrm{~mm}$ and distance from the side $15 \mathrm{~mm}$. Application position $10 \mathrm{~mm}$ with solvent position $70 \mathrm{~mm}$. Measurement mode was ultraviolet (UV) absorbance/reflectance with scanning wavelength $580 \mathrm{~nm}$., tank saturation $10 \mathrm{~min}$ with filter paper. Total no. of tracks was 8 with the position of first track X-axis $15.0 \mathrm{~mm}$, distance between tracks $10.0 \mathrm{~mm}$, scan start position Y-axis $5.0 \mathrm{~mm}$, scan end position Y $75.0 \mathrm{~mm}$, slit dimensions $4.00 \times 0.30 \mathrm{~mm}$, micro with scanning speed $20 \mathrm{~mm} / \mathrm{s}$, and data resolution $100 \mu \mathrm{m} / \mathrm{step}$. Detector was used as an automatic mode with sensitivity $33 \%$, peak threshold minimum slope-5, peak threshold minimum height-10AU, peak threshold minimum area-50, and peak threshold maximum height -990AU.

The plates were developed in a solvent system in CAMAG glass twin trough chamber $(20 \times 10 \mathrm{~cm})$ with S.S. Lid. Of the various solvent systems tried that containing toluene-ethyl acetate $(8: 2 \mathrm{v} / \mathrm{v})$ gave the best resolution of $\beta$-sitosterol (retention factor-0.91). It was developed up to $80 \mathrm{~mm}$ in the twin trough chamber using mobile phase, dried with the help of air drier, and subjected for TLC scanning using TLC scanner 3 (CAMAG Switzerland) and spots were visualized under UV Light at $254 \mathrm{~nm}, 310 \mathrm{~nm}$, and under visible light at $580 \mathrm{~nm}$. Deuterium and tungsten lamps were the source of radiation utilized.

A $10 \mu$ suitably diluted sample volume was applied in triplicate on a TLC plate. The standard zones were quantified by linear scanning at $580 \mathrm{~nm}$ by use of a TLC Scanner III CAMAG. Data of peak height and peak area of each spot were recorded. The purity of $\beta$-sitosterol bands was confirmed by comparing the absorption spectra at start, middle, and end position of the bands. The calibration curve was prepared by plotting concentration (microgram/spot) versus peak area corresponding to each spot. Hence, the amount of $\beta$-sitosterol in different samples was calculated using the respective calibration curve. The plates were developed and scanned at $580 \mathrm{~nm}$. The peak areas and absorption spectra were recorded. Concentration of the metabolite in sample was calculated by considering the sample initially taken and dilution factors. Quantitative evaluation of the plate was performed in the remission/absorption mode at $580 \mathrm{~nm}$ with the following conditions slit width $4.00 \times 0.30 \mathrm{~mm}$, micro scanning speed $20 \mathrm{~mm} /$ second and data resolution $100 \mu \mathrm{m} / \mathrm{step}$.

\section{RESULT AND DISCUSSION}

HPTLC is a reliable analytical technique for quantification of analytes at micro and nanogram levels [11]. It is a useful technique reason being its low operating cost, less analysis time, high sample throughput, and need for minimum sample clean-up. HPTLC offers precise control over sample application, chromatographic development, derivatization, detection, and determination $[12,13]$.

HPTLC studies of methanolic sample extract for identification of stigmasterol, quercetin, and kaempferol simultaneously in Indigofera tinctoria and quantification of kaempferol and quercetin in various medicinal plants has been performed [14,15]. Isolation and identification of stigmasterol and $\beta$-sitosterol through HPTLC from methanolic extract of root bark of Calotropis gigantea and quantification of stigmasterol and lupeol from Ficus religiosa $[16,17]$ and lupeol from Andrographis echioides leaves has been done [18]. These types of quantification studies thus stand useful in suggesting a wide array of possible therapeutics from natural sources.

In the present study, $\beta$-sitosterol was estimated and quantified from four different plant parts viz. leaf, stem, seed, and callus (in vitro) samples of $M$. aegyptia and $M$. dissecta, respectively, as it is a medicinally important compound and has antifungal, antibacterial, and anti-inflammatory activities and is also used to treat asthma, arthritis, allergies, and cancer.

HPTLC studies revealed resolution of bands of $\beta$-Sitosterol at $R_{\mathrm{f}}-0.91$ (Fig. 2). The identity of the bands of $\beta$-Sitosterol in the samples was confirmed by overlapping their UV absorption spectrum with that of standards. The calibration curve was plotted using concentration $(\mu \mathrm{g} / \mathrm{spot})$ and peak area of each spot. The amount of $\beta$-sitosterol in different samples was calculated using the calibration curve. The plates were developed at $580 \mathrm{~nm}$. $M$. dissecta leaf sample reported to contain $\beta$-sitosterol in quantity $4.6 \mathrm{ng} / \mu \mathrm{l}$. The presence of such a useful metabolite in vivo makes this plant phytopharmaceutical important.

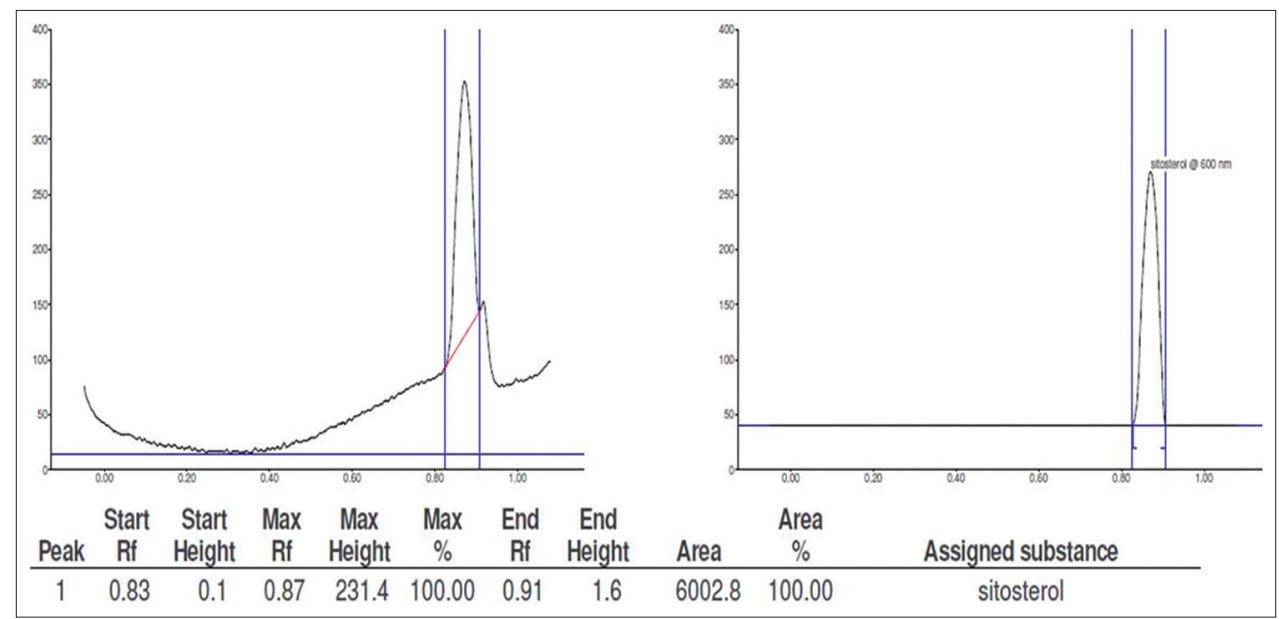

Fig. 2: Chromatogram of standard solution of $\beta$-Sitosterol peak (Amount/Fraction $\approx 1200 \mathrm{ng}$ ) 


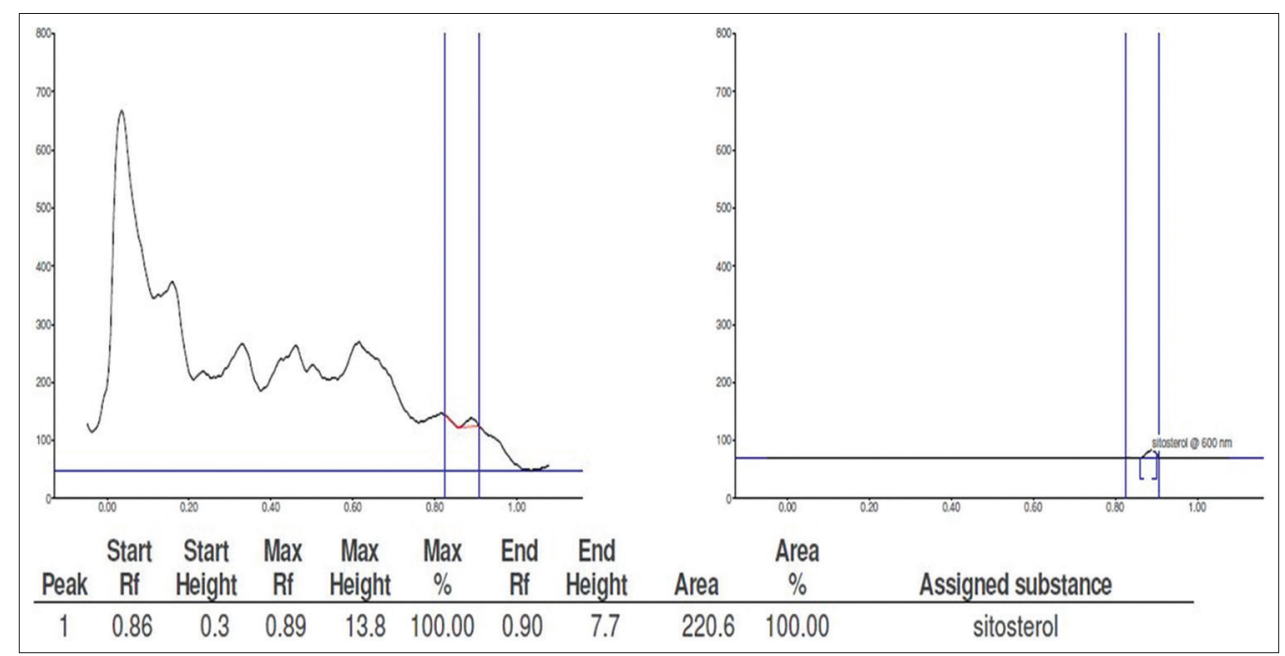

Fig. 3: Chromatogram of $\beta$-sitosterol reported in leaf sample extract of Merremia dissecta

\section{CONCLUSION}

Advantages of HPTLC include the capability to detect more compounds than HPLC simultaneously and it can identify compounds with no UV absorption by reagent spraying. It also provides semi-quantitative information on the major active constituents of a drug or drug preparation, thus enabling an assessment of drug quality. Furthermore, the colorful picture in HPTLC provides extra intuitive parameters of visible color and/or fluorescence [16]. Realizing the medicinal importance of $\beta$-sitosterol, the present study was performed and it was found that $M$. dissecta leaf sample contained $\beta$-sitosterol (4.6 nanogram/microliter, Fig. 3).

\section{CONFLICTS OF INTEREST}

The authors have no conflicts of interest.

\section{ACKNOWLEDGEMENT}

The authors are highly thankful to Ayushraj Enterprises Pvt. Ltd., Jaipur, for providing their HPTLC facility to carry out the research work.

\section{AUTHORS' CONTRIBUTIONS}

Dr. Ridhi Joshi carried out all the laboratory work as part of her Ph.D. and compiled the manuscript. Dr. Vidya Patni and Dr. Preeti Mishra analyzed the data and guided throughout the research work. Dr. Rishikesh Meena finalized the manuscript. All the authors read and approved the final manuscript.

\section{AUTHORS' FUNDING}

This research was funded by UGC (UGC-JRF).

\section{REFERENCES}

1. Dawane V, Fulekar MH. High-performance thin layer chromatography (HPTLC) fingerprinting pattern of mangrove Avicennia marina. Int J Pharm Pharm Sci 2017;9:65-72.

2. Tatu A, Miettinen A, Helena G. Ineffective decrease of serum cholesterol by simvastatin in a subgroup of hypercholesterolemic coronary patients. Atherosclerosis 2002;164:147-52.

3. MacLatchy DL, Der V, Kraak GJ. The phytoestrogen beta-sitosterol alters the reproductive endocrine status of goldfish. Toxicol Appl
Pharmacol 1995;134:305-12.

4. Zak A, Vecka M, Tvrzicka E, Hruby M, Novak F, Papezova H, et al. Composition of plasma fatty acids and non-cholesterol sterols in anorexia nervosa. Physiol Res 2005;54:443-51.

5. Awad AB, Fink CS. Phytosterols as anticancer dietary components: Evidence and mechanism of action. J Nutr 2000;1:2127-30.

6. Bouic PJ, Etsebeth S, Liebenberg RW, Albrecht CF, Pegel K, Van Jaarsveld PP. Beta-sitosterol and beta-sitosterol glucoside stimulate human peripheral blood lymphocyte proliferation: Implications for their use as an immune modulatory vitamin combination. Int $\mathbf{J}$ Immunopharmacol 1996;18:693-700.

7. Frank N, Andrews FM, Elliott SB, Lew J, Boston RC. Effects of rice bran oil on plasma lipid concentrations, lipoprotein composition, and glucose dynamics in mares. J Anim Sci 2005;83:2509-18.

8. Awad AB, Chan KC, Downie AC, Fink CS. Peanuts as a source of beta-sitosterol, a sterol with anticancer properties. Nutr Cancer 2000;36:238-41.

9. Bidawat S. Evaluation of Balanites aegyptiaca (Hingota) an Arid Zone Medicinal Plant for Phytochemically Important Metabolites, Ph. D Thesis. India, Ajmer: M.D.S. University; 2006.

10. Nile SH, Park SW. HPTLC analysis, antioxidant and antigout activity of Indian plants. Iran J Pharm Res 2014;13:531-9.

11. Kamboj A, Saluja A. Development of validated HPTLC method for quantification of stigmasterol from leaf and stem of Bryophyllum pinnatum. Arabian J Chem 2017;10:2644-50.

12. Mishra J, Singh RD, Jadon VS, Gusain MP, Aradhana, HPTLC profile of quercetin content of common bean (Uttarakhand) landraces growing in Uttarakhand. Am J Food Technol 2012;7: 96-100.

13. Srinivasa H, Bagul M, Padh H. A rapid densitometric method for the quantification of luteolin in medicinal plants using HPTLC. Chromatographia 2004;60:131-4

14. Felicia FA, Muthulingam M. Phytochemical and HPTLC studies of methanolic extract of Indigofera tinctoria (Fabaceae). Int J Pharm Life Sci 2012;3:1670-74.

15. Bhandare SB, Laddha KS. Simultaneous quantification of kaempferol and quercetin in medicinal plants using HPTLC. Int J Pharm Sci Res 2016;7:2379-84.

16. Habib MR, Nikkon F, Rahman M, Haque ME, Karim MR. Isolation of stigmasterol and B sitosterol from methanolic extract of root bark of Calotropis gigantean (Linn.) Pak J Biol Sci 2007;10:4174-6.

17. Rathee D, Rathee S, Rathee P, Deep A, Anandjiwala S, Rathee D. HPTLC densitometric quantification of stigmasterol and lupeol from Ficus religiosa. Arabian J Chem 2015;8:366-71.

18. Gurupriya S, Cathrine I, Pratheema P. HPTLC method for the determination of lupeol from Andrographis echioides leaves. Int $\mathrm{J}$ Pharm Pharm Sci 2018;10:102-7. 